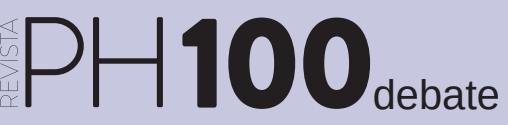

a debate Repositorios y redes sociales académicas para la transferencia del conocimiento abierto

| coordina Remedios Melero Melero

\title{
De la aldea pública de los repositorios institucionales a la metrópoli privada de ResearchGate
}

\author{
Enrique Orduña-Malea | Dpto. de Comunicación Audiovisual, Documentación e Historia del Arte, Universitat Politècnica de \\ València
}

URL de la contribución <www.iaph.es/revistaph/index.php/revistaph/article/view/4659>

La creación de Internet (controlada y regulada por la comunidad científica durante años) supuso un salto cualitativo a la hora de acceder a resultados de investigación, disponibles en Red a través de un sistema de información descentralizado.

La comunidad científica comenzó no sólo a compartir contenidos (datos brutos y preprints) a través de servidores FTP sino a mantener correspondencia (emails, chats). Es decir, a comunicarse. La Web, diseñada originalmente para acceder (mediante http), conectar (mediante url) y visualizar (mediante html) documentación científica, vino a simplificar y generalizar su uso.

Los primeros repositorios de la historia, tal y como los entendemos hoy día, fueron temáticos. Entre éstos destaca Los Alamos National Laboratory Preprint Archive (ahora Arxiv), lanzado en 1991 como un servidor de preprints (e-prints) en el campo de la Física (GINSPARG,

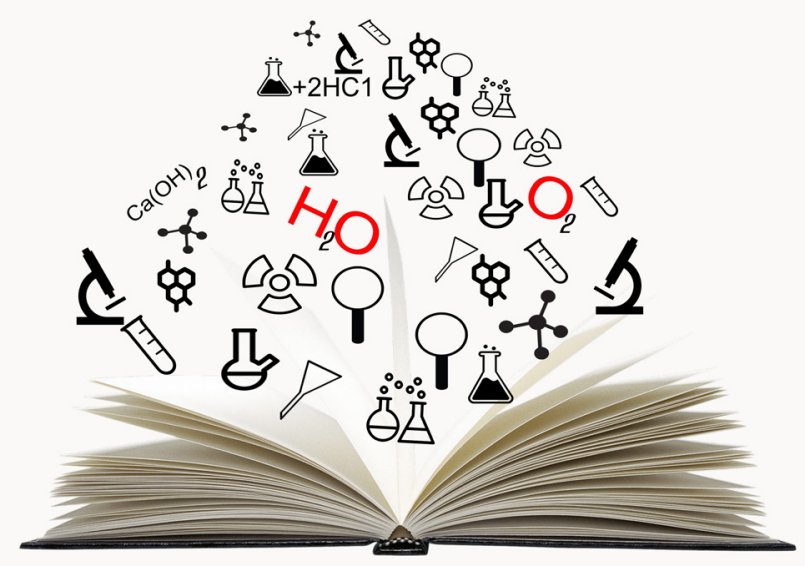

Se ha asistido a la eclosión del término Open Access
2011). Su popularidad vino dada por tres razones fundamentalmente: contrastar (fast open peer review), reclamar (prioridad del descubrimiento) y difundir (reputación) resultados. El término "open access" todavía no formaba parte del vocabulario de la comunidad científica. Este concepto eclosionó posteriormente, aunque su popularidad ha ido disminuyendo con el tiempo, si atendemos al número de veces que este término es buscado en Google.

La aparición de los repositorios institucionales se produjo en un contexto diferente. EPrints (2000) aparece tras la celebración de la Santa Fe Convention for the Open Archives Initiative (1999) y DSpace (2002) tras la Budapest Open Access Initiative (2001), en plena ebullición del movimiento de acceso abierto.

La existencia de software potente y gratuito democratizó la implantación de repositorios en universidades de todo el mundo. No obstante, su aplicación vino acompañada de distintos errores:

1) La personalización del software no era sencilla, lo que provocó que muchos repositorios se instalasen con la configuración por defecto, que transmitía dejadez y falta de identidad institucional.

2) Los procedimientos de envío de documentos eran tediosos y hechos para profesionales de la información, no para el usuario final. Como consecuencia, la descripción y clasificación de documentos solía ser de baja calidad. Esto suponía un esfuerzo extra para el personal bibliotecario, que debía mejorar la calidad de la información para hacerla útil con escasos recursos humanos. 
3) La gestión no era rápida en la aceptación de envíos y estaba sujeta a normas de funcionamiento no siempre alineadas con las necesidades de difusión del personal científico.

4) No permitían la comunicación entre usuarios, especialmente a nivel de comunidad. Una investigadora de química inorgánica y un investigador de teoría de la señal podrán compartir afiliación institucional, pero no comunidad científica.

5) No constituían recursos de información de interés: no eran utilizados para buscar información ni aportaban servicios de valor añadido. Es decir, eran cementerios de PDFs.

Estas circunstancias propiciaron que muchos repositorios institucionales se acabaran convirtiendo en auténticas aldeas académicas. No obstante, la historia da un cambio brusco con la aparición de las redes sociales académicas, entre las que destaca ResearchGate (RG), fundada en 2008 (ORDUÑA-MALEA, MARTÍN-MARTíN, DELGADO-LÓPEZ-CÓZAR, 2016).

RG es una plataforma orientada a compartir publicaciones académicas, un híbrido entre repositorio temático (usuarios de cualquier institución y campo pueden depositar documentos) e institucional (se generan perfiles institucionales).

Sin embargo, RG es desarrollado por una empresa (con objetivos de monetización, actualmente centrados en la publicidad y búsqueda de empleo), de gran tamaño (emplea a más de 200 empleados) y con capital de inversión (Tenaya Capital, Goldman Sachs, Wellcome Trust, etc.).

RG contiene actualmente (abril 2020) más de 100 millones de documentos y 17 millones de usuarios, y recibe cerca de 140 millones de visitas mensuales. Estos datos son explotados por la empresa para ofrecer una serie de servicios de valor añadido, entre los que destaca la difusión general y selectiva de contenidos (artículos, datos,

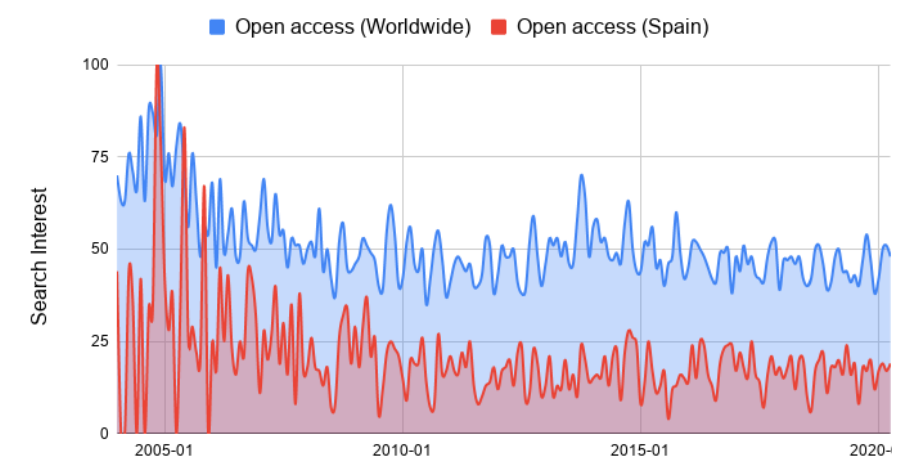

Evolución de la popularidad de búsqueda del término "Open Access" | fuente Google Trends

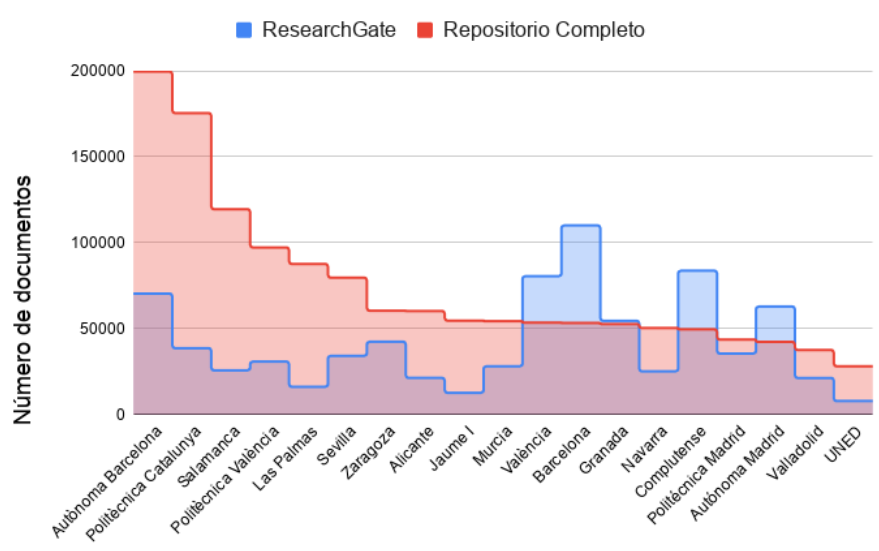

Número de documentos depositados en repositorios institucionales y en el perfil institucional en ResearchGate para universidades españolas | fuente elaboración propia

posters, presentaciones, etc.) de forma instantánea y sencilla.

La plataforma se convierte así en un concentrador de métricas donde todas las interacciones que recibe cada documento (visitas, citas, comentarios, recomendaciones) se agregan a nivel de usuario e institución. Cada usuario puede además conectarse con otros usuarios (seguir sus publicaciones o enviar mensajes privados), generar alertas (de trabajos, autores o temas) y, por supuesto, difundir su currículum académico. Todo ello de forma gratuita y a escala global. RG es una metrópoli académica donde los ciudadanos 
a debate Repositorios y redes sociales académicas para la transferencia del conocimiento abierto

| coordina Remedios Melero Melero

construyen su reputación académica y establecen sus relaciones sociales.

La explicación del éxito de RG viene derivada de la aplicación de un sistema de recompensas basado en técnicas de gamificación, centradas en mantener atentos y entretenidos a los usuarios, que utilizan el sistema de forma inversiva. Una práctica similar a la utilizada por Facebook.

Los usuarios depositan en RG sus publicaciones aun sin existir ningún mandato para su uso (BORREGO, 2017). Es más, a fecha de abril de 2020, se detectan 45 universidades españolas en las que la cantidad de ítems depositados en RG es superior a la existente en sus repositorios. A pesar de la existencia de documentos duplicados en RG, este dato es negativo especialmente si consideramos que en los repositorios se incluyen documentos que no son publicaciones científicas (revistas propias, material docente, etc.). Sólo en algunos repositorios se puede filtrar por colección 'investigación', pero la composición de esta colección difiere entre universidades.

Más allá de problemas de copyright (JAMALI, 2017), que perjudican a las editoriales, o de identidad (YAN Y ZHANG, 2018), que perjudican a las universidades, el uso de RG plantea importantes dudas. Podría convertirse en un servicio exclusivamente de pago, podría cerrar o ser adquirida por otra empresa, ¿qué pasaría entonces con todos sus (nuestros) contenidos y métricas, si sólo los depositamos allí?

Llegados a este punto, cabe preguntarse si una empresa alemana ha logrado desde cero desarrollar esta metrópoli, ¿por qué no lo ha podido lograr ningún consorcio internacional de universidades o la propia Comisión Europea?

Los repositorios institucionales deben transformarse de forma integral si desean sobrevivir como nodos influyentes en el ecosistema científico. De lo contrario, quedarán diluidos como meros alimentadores de otros sistemas de información (como Google Scholar o ResearchGate), utilizados por la comunidad científica pero controlados por empresas de servicios privadas.

\section{BIBLIOGRAFÍA}

- BORREGo, A. (2017) Institutional repositories versus ResearchGate: The depositing habits of Spanish researchers. Learned publishing, vol. 30, n. ${ }^{\circ}, 3,2017$, pp. 185-192

- GINSPARG, P. (2011) ArXiv at 20. Nature, vol. 476, n. ${ }^{\circ} 7359$, 2011, pp. 145-147

- JAMALI, H. R. (2017) Copyright compliance and infringement in ResearchGate full-text journal articles. Scientometrics, vol. 112, n. $^{\circ} 1,2017$, pp. 241-254

- ORDUÑA-MALEA, E.; MARTíN-MARTÍN, A.; DELGADOLÓPEZ-CÓZAR, E. (2016) ResearchGate como fuente de evaluación científica: desvelando sus aplicaciones bibliométricas. El profesional de la información, vol. 25, n. ${ }^{\circ} 2$, 2016, pp. 303-310

- YAN, W.; ZHANG, Y. (2018) Research universities on the ResearchGate social networking site: An examination of institutional differences, research activity level, and social networks formed. Journal of Informetrics, vol. 12, n. ${ }^{\circ} 1,2018$, pp. $385-400$ 